\title{
Synergistic effect of methyljasmonate and cyclodextrin on stilbene biosynthesis pathway gene expression and resveratrol production in Monastrell grapevine cell cultures
}

\author{
Diego Lijavetzky ${ }^{\dagger 1,2}$, Lorena Almagro ${ }^{\dagger 3}$, Sarai Belchi-Navarro3, \\ José M Martínez-Zapater ${ }^{1,4}$, Roque Bru ${ }^{5}$ and Maria A Pedreño*3
}

Address: ${ }^{1}$ Departamento de Genética Molecular de Plantas, Centro Nacional de Biotecnología, Consejo Superior de Investigaciones Científicas (CSIC), C/Darwin 3, 28049 Madrid, Spain, ${ }^{2}$ Cátedra de Química Orgánica y Biológica, Facultad de Ciencias Agrarias, Universidad Nacional de Cuyo-Consejo Nacional de Investigaciones Científicas y Técnicas (CONICET), M5528AHB Chacras de Coria, Argentina, ${ }^{3}$ Departamento de Biología Vegetal, Facultad de Biología, Universidad de Murcia, Campus de Espinardo, E-30100 Murcia, Spain, ${ }^{4}$ Instituto de Ciencias de la Vid y el Vino (Consejo Superior de Investigaciones Científicas, Universidad de La Rioja, Gobierno de La Rioja), Campus de la Universidad de La Rioja, C/ Madre de Dios 51, 26006 Logroño, Spain and ${ }^{5}$ Departamento de Agroquímica y Bioquímica, Facultad de Ciencias, Universidad de Alicante, Apartado 99, E-03080 Alicante, Spain

Email: Diego Lijavetzky - dlijavetzky@cnb.csic.es; Lorena Almagro - lorena.almagro@alu.um.es; Sarai Belchi-Navarro - saraibn@um.es; José M Martínez-Zapater - zapater@cnb.csic.es; Roque Bru - Roque.Bru@ua.es; Maria A Pedreño* - mpedreno@um.es

* Corresponding author †Equal contributors

Published: 22 December 2008

BMC Research Notes 2008, I:132 doi:10.1186/1756-0500-1-132
Received: II July 2008

Accepted: 22 December 2008

This article is available from: http://www.biomedcentral.com/I756-0500/I//32

(C) 2008 Pedreño et al; licensee BioMed Central Ltd.

This is an Open Access article distributed under the terms of the Creative Commons Attribution License (http://creativecommons.org/licenses/by/2.0), which permits unrestricted use, distribution, and reproduction in any medium, provided the original work is properly cited.

\begin{abstract}
Background: Plant cell cultures have been shown as feasible systems for the production of secondary metabolites, being the elicitation with biotic or abiotic stimuli the most efficient strategy to increase the production of those metabolites. Vitaceae phytoalexins constitute a group of molecules belonging to the stilbene family which are derivatives of the trans-resveratrol structure and are produced by plants and cell cultures as a response to biotic and abiotic stresses. The potential benefits of resveratrol on human health have made it one of the most thoroughly studied phytochemical molecules. The aim of this study was to evaluate the elicitor effect of both cyclodextrin (CD) and methyljasmonate (MeJA) on grapevine cell cultures by carrying out a quantitative analysis of their role on resveratrol production and on the expression of stilbene biosynthetic genes in Vitis vinifera cv Monastrell albino cell suspension cultures.

Findings: MeJA and CD significantly but transiently induced the expression of stilbene biosynthetic genes when independently used to treat grapevine cells. This expression correlated with resveratrol production in CD-treated cells but not in MejA-treated cells, which growth was drastically affected. In the combined treatment of $C D$ and MeJA cell growth was similarly affected, however resveratrol production was almost one order of magnitude higher, in correlation with maximum expression values for stilbene biosynthetic genes.

Conclusion: The effect of MeJA on cell division combined with a true and strong elicitor like CD could be responsible for the observed synergistic effect of both compounds on resveratrol production and on the expression of genes in the stilbene pathway.
\end{abstract}




\section{Background}

The more relevant Vitaceae phytoalexins comprise a group of molecules belonging to the stilbene family $[1,2]$, which are derivatives of the trans-resveratrol structure $(3,5,4$ '-trihydroxystilbene). In addition to trans-resveratrol derived molecules, other oligomers produced by its oxidation and generically known as viniferins have been found as the result of infection or stress [3]. Different naturally occurring stilbenes like resveratrol, pterostilbene, piceatannol and resveratrol glucoside derivatives [4] are known to be strong antioxidants. In particular, the potential benefits of resveratrol on human health have made it one of the most thoroughly studied phytochemical molecules [5]. See de la Lastra and Villegas [6] for a review of the reported resveratrol effects.

Stilbenes are synthesized via the phenylpropanoid/ malonate pathway from phenylalanine that, in turn, is converted into cinnamic acid by phenylalanine ammonia lyase (PAL). The consecutive action of cinnamate 4hydroxylase $(\mathrm{C} 4 \mathrm{H})$ and 4-coumarate CoA ligase (4CL) transform cinnamic acid into p-coumaryl-CoA. Derived compounds, collectively referred to as polyphenols, are originated at this branching point through the action of enzymes chalcone synthase (CHS) and stilbene synthase (STS) for flavonoids and stilbenoids, respectively [2].

Vitis vinifera cell cultures have been used in several studies to explore the factors involved in the induction and regulation of stilbene biosynthesis and metabolism $[7,8]$. Jasmonic acid (JA) and its more active derivative methyljasmonate (MeJA) have been proposed as key compounds of the signal transduction pathway involved in the elicitation of secondary metabolite biosynthesis which takes part in plant defence reactions [9]. Application of MeJA on grapevine leaves and plant cell suspension cultures can induce the accumulation of stilbenes $[10,11]$. However, the reported amount of stilbenes secreted to the medium in MeJA-treated cell cultures is negligible $[8,12]$.

Cyclodextrins (CDs) are naturally occurring cyclic oligosaccharides derived from starch. Addition of 2,6 dimethyl- $\beta$-ciclodextrin (DIMEB) to grapevine cell cultures induces both resveratrol biosynthesis and its accumulation in the culture media [13]. Among the differently modified $\beta$-cyclodextrins, the methylated and hydroxypropylated caused the highest production of this phytoalexin, which is translocated to the cell walls and accumulates in the culture media $[14,15]$.

The aim of this study was to evaluate the elicitor effect of joint applications of CDs and MeJA on grapevine cell cultures by carrying out a quantitative analysis of their role on resveratrol production. We also monitored the expres- sion of several genes encoding key enzymes in the phenylpropanoid pathway, including those involved in resveratrol biosynthesis, to determine the relationship between resveratrol accumulation in the medium after elicitation and the regulation of gene expression. A synergistic interaction between $\mathrm{CD}$ and MeJA on resveratrol production and on the expression of stilbene biosynthesis related genes is discussed.

\section{Results \\ MeJA but not CD affects cell growth}

Grapevine cell cultures were treated with DIMEB (CD), methyljasmonate (MeJA) and a combination of CD and MeJA. As shown in Figure 1, CD-treated cells displayed a similar sustained biomass increase (from 7 to over $15 \mathrm{~g}$ DW $\mathrm{l}^{-1}$ ) and growth curve as control untreated cells indicating that $\mathrm{CD}$ treatment did not affect cell growth. On the other hand, cell cultures treated with MeJA alone or together with CD showed a growth curve (Figure 1) with significantly lower biomass generation (up to 30\% less than control and CD-treated cells). This biomass reduction did not result from massive cell lyses, since no losses in cell viability could be observed by fluorescent microscopy (Additional File 1).

\section{CD and MeJA synergistically induce resveratrol production} To compare the effects of the different treatments in transresveratrol production, the level of this compound was analyzed in the spent medium at different times. Trace amounts of cis-resveratrol were also detected (Additional File 2). As shown in Figure 2, no significant amounts of trans-resveratrol were detected in the spent medium when cell cultures were elicited with MeJA. In contrast, CD treated cell cultures showed a significant production of resveratrol. The level of resveratrol increased linearly until $72 \mathrm{~h}$, and then remained constant for the rest of the experiment until $168 \mathrm{~h}$ (Figure 2). Remarkably, when cells were simultaneously elicited with CD and MeJA, the accumulation of resveratrol in the medium increased exponentially reaching a concentration plateau after $120 \mathrm{~h}$ and a final concentration higher than $1600 \mu$ mole $\mathrm{gDW}^{-1}$, which almost represents one order of magnitude higher than the final concentration obtained in CD treated cells (Figure 2 and Additional File 2). The content of stilbenoids within cells (free and glycosilated forms of trans- and cis-resveratrol) was also analyzed (Additional File 3). No statistically significant differences were found in the total amount of intracellular stilbenoids between MeJA treated cells and the control, while the CD and CD + MeJA treated cells presented a 3- and 20-fold increment in relation to the control cells, respectively. The trans-isomers represented between 80 to $90 \%$ of intracellular stilbenoids. However, as compared to the overall production, endogenous stilbenoids represent less than $1 \%$ of the total stilbenoids. 


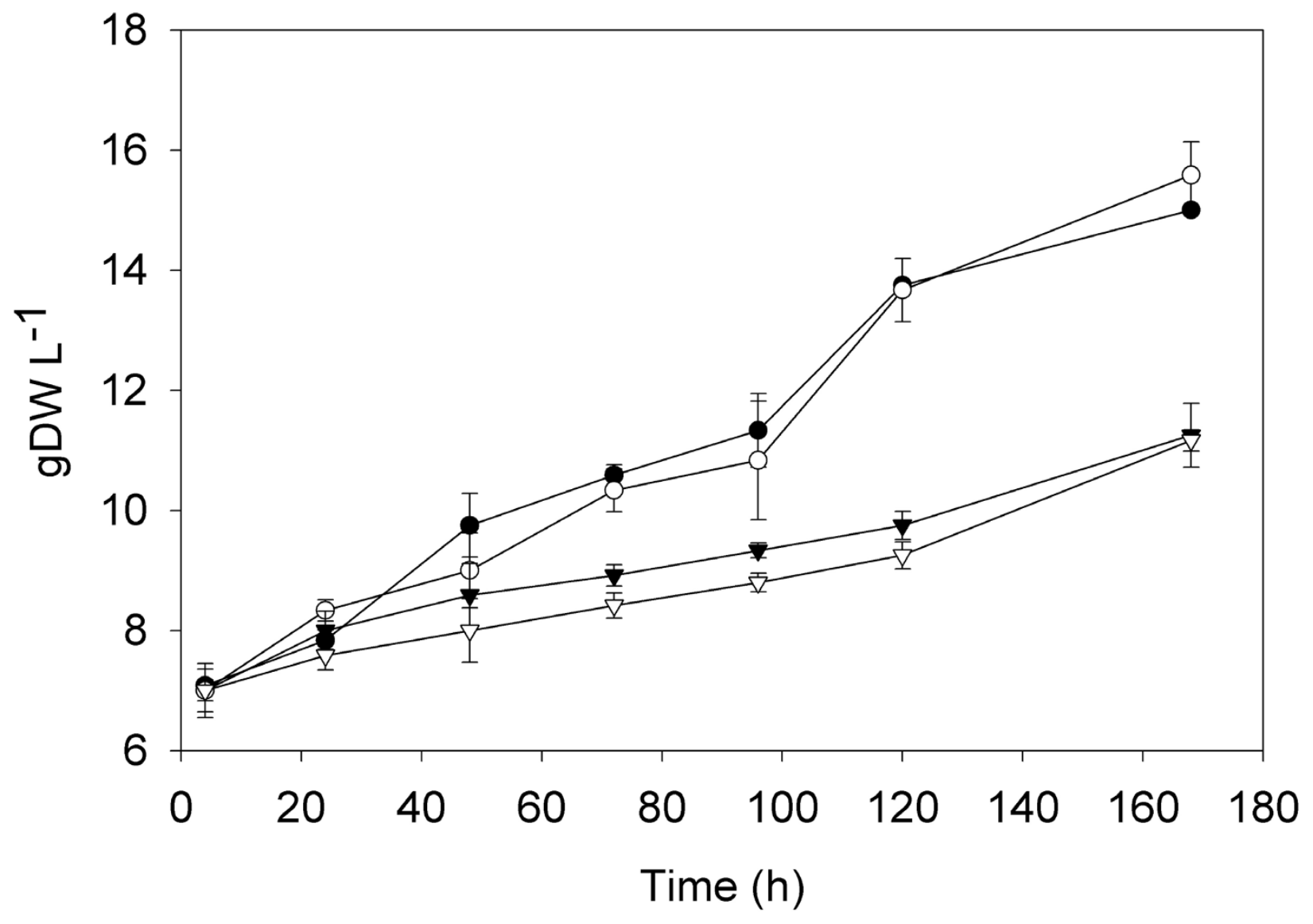

Figure I

Growth curves of grapevine treated cell suspension cultures. (solid circle) Control cells, (open circle) CD treated cells, (solid triangle) MeJA treated cells, (open triangle) CD+MeJA treated cells. Measurements are expressed as $g$ DW $\mathrm{I}^{-1}$ and values are given as the mean \pm standard deviation of three replicates.

Therefore, the extracellular trans-resveratrol correlates with the actual biosynthetic activity of the cells.

\section{$C D$ and MeJA synergistically and specifically induce the expression of STS and the general phenylpropanoid pathway}

In order to analyze the relationship between levels of phytoalexin accumulation in the medium and the expression of related biosynthetic genes, we performed real time qRTPCR analyses of two stilbene synthase (STS) genes and different genes from the phenylpropanoid pathway. The relative expression levels of these two STS genes were quantified at five different time points through the incubation of the cell cultures with CD, MeJA or the combined treatment with CD and MeJA. Both STS genes showed the same expression profile in all the treatments, although STS1 expression was one order of magnitude higher than STS2 (Figure 3). In control cell cultures and in all the treat- ments, STS expression was higher at $4 \mathrm{~h}$, presumably as a consequence of the treatments setup. In agreement with this possibility, STS expression in control cells dropped 24 $\mathrm{h}$ after the treatment and almost disappeared during the rest of the incubation. In contrast, $24 \mathrm{~h}$ after the treatment, we detected a marked expression of STS in CD treated cells, slowly decreasing until the end of the experiment (Figure 3). Expression of STS in the MeJA incubated cells at $24 \mathrm{~h}$ was similar to that observed in the CD treatment but rose significantly at $72 \mathrm{~h}$ to reach its maximum values. The more notable results were observed in cell cultures elicited with both CD and MeJA. Expression of STS was higher in this treatment than in all the other treatments at all time points (Figure 3). Similarly to what was observed in the MeJA treatment, a maximum of expression of both STS genes was observed at $72 \mathrm{~h}$. Later expression stabilized (or even decreased) at $120 \mathrm{~h}$ to increase again at the last analyzed point $168 \mathrm{~h}$. During the first 


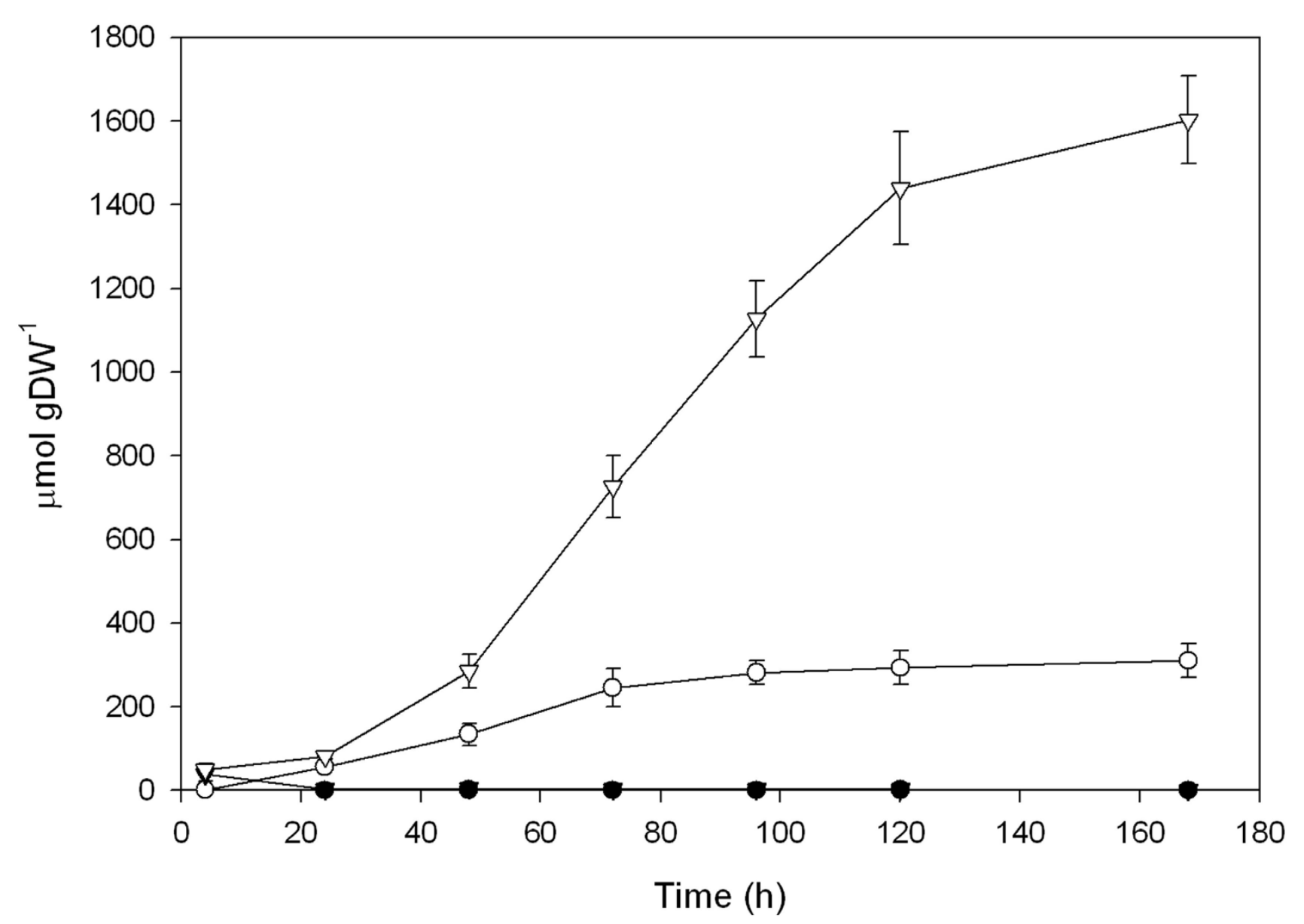

Figure 2

Resveratrol accumulation of grapevine treated cell suspension cultures. (solid circle) Control cells, (open circle) CD treated cells, (solid triangle) MeJA treated cells, (open triangle) CD+MejA treated cells. The accumulation of trans-resveratrol in the spent medium was measured as $\mu \mathrm{mol} \mathrm{g} \mathrm{DW}^{-1}$ and values are given as the mean \pm standard deviation of three replicates.

three days of treatment, expression of STS in the combined treatment was relatively similar to the sum of the $\mathrm{CD}$ and MeJA effects. However, after $120 \mathrm{~h}$, the combined treatment of CD and MeJA yielded expression values that seem to reveal a synergistic interaction between those two compounds (Figure 3).

To evaluate the specificity of the stilbene pathway induction, we analyzed the relative expression of the general phenylpropanoid pathway genes (PAL, C4H, 4CL) as well as that of CCR and CHS in treated cell cultures. These last two genes encode key enzymes of stilbene alternative pathways: $C H S$ catalyzes the first step in the anthocyanin and isoflavonoid biosynthetic pathways, and CCR plays a similar role in the lignin biosynthetic pathway. Gene expression was evaluated at the same time points described above. The expression profiles of $P A L, C 4 H$, and $4 C L$ were almost identical to those of STS with an earlier induction in the case of the combined treatment of CD and MeJA (Figure 3). On the other hand, the relative expression of CCR was very low, about one order of magnitude lower than that of the less expressed gene analyzed in the pathway (i.e. 4CL, Figure 3). Moreover, none of two $\mathrm{CHS}$ assayed genes displayed any detectable expression along the whole experiment (Figure 3).

\section{Discussion}

The results described here show that the combined addition of MeJA and CD to $V$. vinifera $\mathrm{cv}$. Monastrell albino cell cultures yields a much higher resveratrol accumulation than the sum of the individual additions. In our experiments, the combined treatment increased seven 

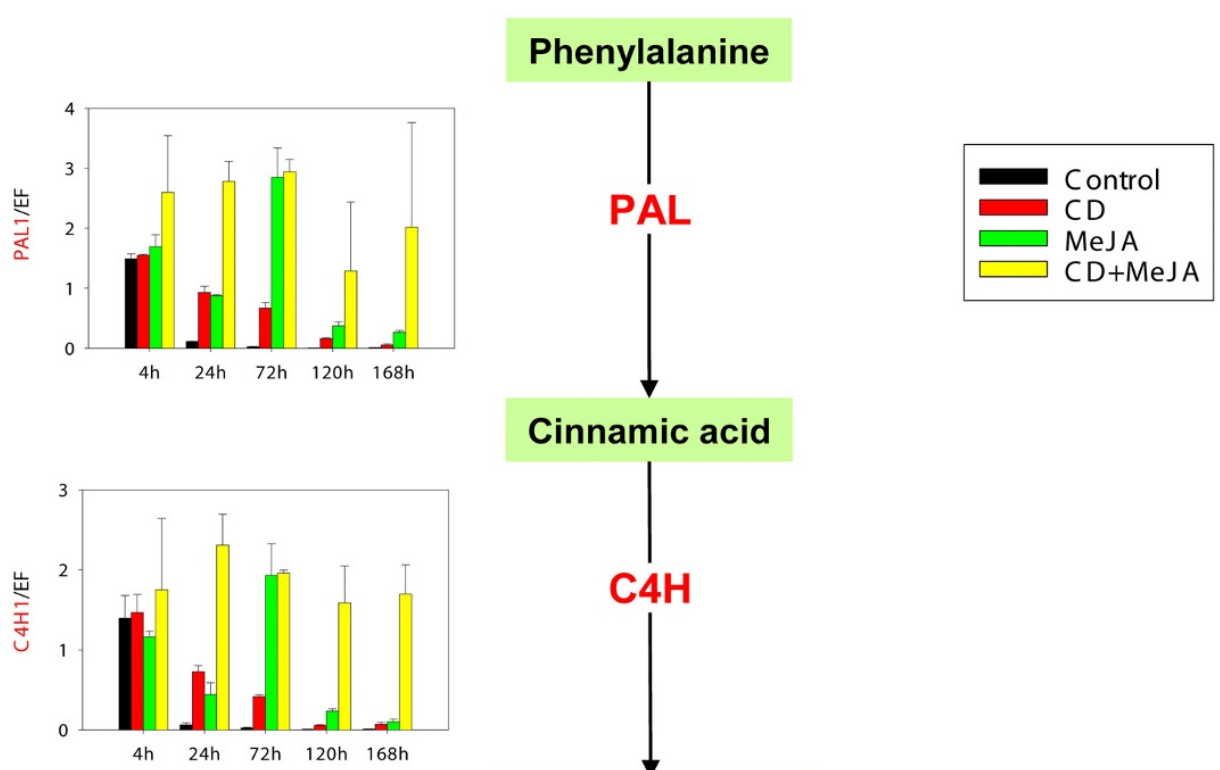

\section{Cinnamic acid}
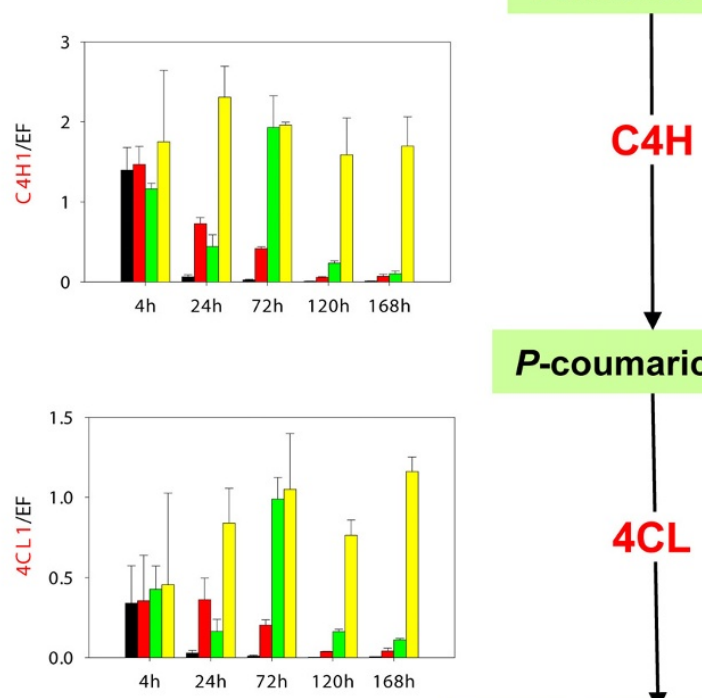

\section{$P$-coumaric acid}
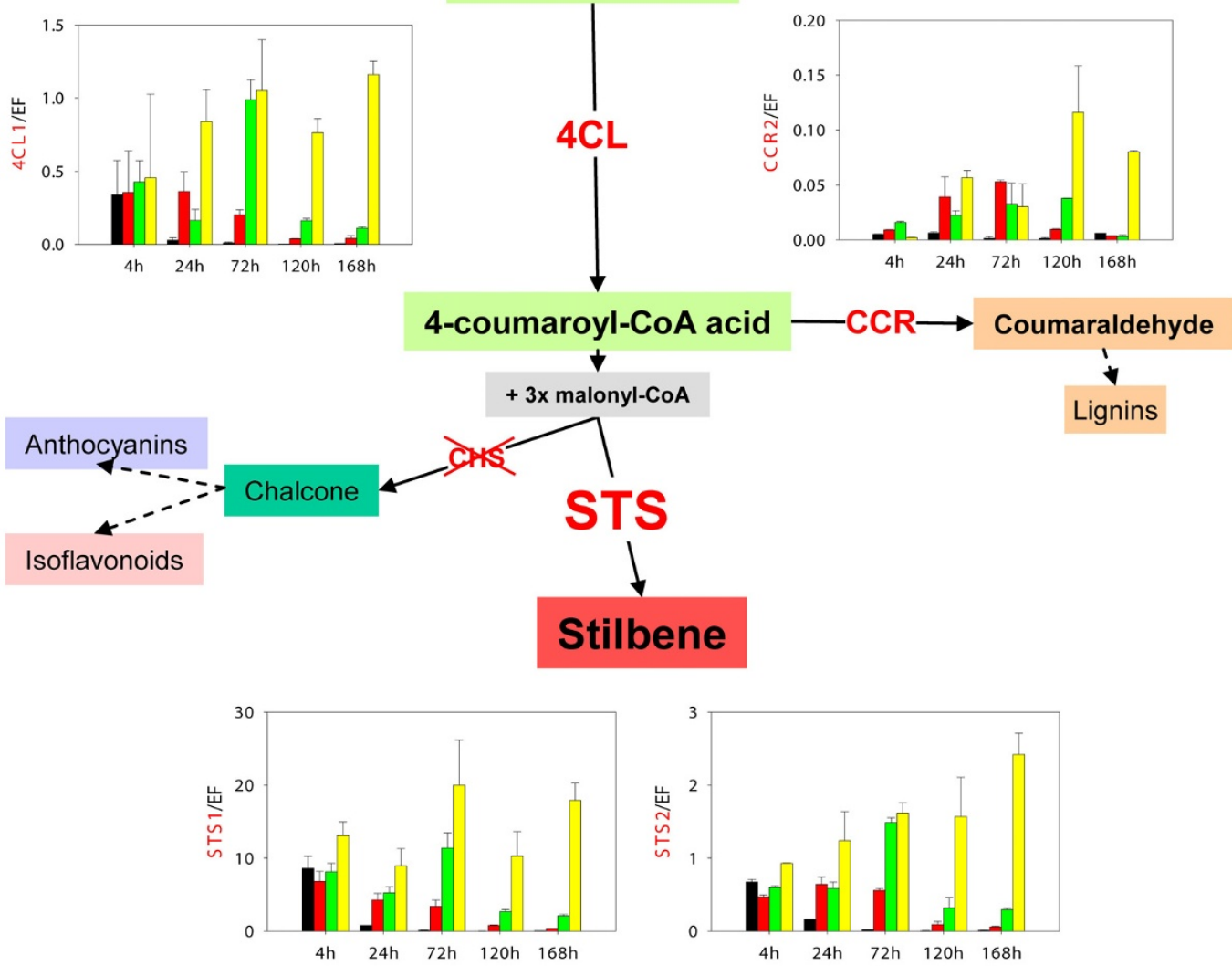

Figure 3

Relative expression of phenylpropanoid-related genes in grapevine treated cell suspension cultures. PAL, C4H, $4 C L$, STS, CHS and CCR transcribed mRNAs were analysed by real-time quantitative RT-PCR. Levels of transcripts were calculated using the standard curve method with grapevine $\mathrm{EF} \alpha \mathrm{I}$ gene as internal control. Values are given as the mean \pm standard deviation of three replicates. 
times the yield of resveratrol when compared to CDs alone. This final resveratrol level $\left(1600 \mu \mathrm{mole}_{\mathrm{gDW}}{ }^{-1}\right)$ represents an increase between 10- and more than 1000fold with respect to previous reports $[8,12,16]$. The expression analysis of this response shows that both elicitors stimulated the expression of $P A L, C 4 H, 4 C L$ and STS independently of the anthocyanins/isoflavonoids (CHS) and lignins (CCR) pathways and therefore both induce stilbene biosynthetic genes in a highly specific way, in agreement to results reported by Saigne-Soulard et al.[17]. Furthermore, the synergistic interaction of both elicitors on resveratrol production (Figure 2) seems to be the result of their synergistic effect on the expression of biosynthetic genes (Figure 3).

In MeJA-treated cells, a significant reduction in cell growth was observed (Figure 1) in parallel with a strong induction of the general phenylpropanoid pathway (Figure 3), as recently reported for Arabidopsis cell suspension cultures [18]. However, although STS expression was highly induced (Figure 3), no significant amounts of resveratrol were detected in the spent media (Figure 2). Such discrepancy could be due to either post-transcriptional and/or post-translational regulatory mechanisms $[12,16,19]$.

CD elicited cells effectively produced significant amounts of resveratrol (Figure 2) in correlation with a transient expression of the central phenylpropanoid enzymes and STS genes (Figure 3). Furthermore, most (or all) the resveratrol synthesized up to $72 \mathrm{~h}$ remained in the culture medium until the end of the assay (Figure 2). CDs are able to form inclusion complexes with stilbene compounds, such as trans-resveratrol and diethylstilbestrol $[13,20]$, which could protect resveratrol from oxidation or glucosylation. This could explain the observation that, although STS expression dropped after $72 \mathrm{~h}$ in the CD treatment (Figure 3), the amount of resveratrol stayed constant (Figure 2). In contrast to the effect of MeJA, CD treated cells were not altered in their growth, displaying a similar biomass growth curve as control cells (Figure 1). Since both complexed and uncomplexed CD molecules remain in the culture medium during the whole assay, the transient gene expression and the high but limited production of resveratrol must be the result of additional regulatory mechanisms. Given the regular growth curve of the CD-treated cell cultures it is tentative to propose that engagement of cells in active division could somehow compete with further production of resveratrol after a transient elicitation response. In fact, Naill \& Roberts [21] observed that most metabolite productive cells in Taxus cuspidata suspension cultures were in the $G_{0} / G_{1}$ phase of the cell cycle (i.e. non-cycling cells) and this stage was suggested as the most specialised for accumulation of secondary metabolites.
In agreement with the previous hypothesis, when both $\mathrm{CD}$ and MeJA were simultaneously added to the culture medium, they caused a significant reduction in cell growth (Figure 1) as well as a sustainable maximum expression of STS and central phenylpropanoid genes, even after $168 \mathrm{~h}$ (Figure 3), which was paralleled by a maximum resveratrol accumulation in the medium (Figure 2). We believe that the blockage in cell division and metabolic rearrangement likely caused by MeJA [18] could place the cells in a non-cycling state [21] allowing a sustained elicitation by $\mathrm{CD}$.

It has been suggested that MeJA may induce a subset of secondary metabolite biosynthetic genes which could modulate expression of genes and accumulation of compounds induced by elicitors $[22,23]$. Although we cannot completely discard this possibility, we show that the synergistic effect observed on resveratrol production is related with a synergistic effect on the expression of the same set of stilbene biosynthetic genes induced by CD (Figure 3). The observed effects of MeJA on cell suspension growth and the recent characterization of MeJA effects on Arabidopsis cell cultures open the possibility to propose an alternative hypothesis to explain this synergy based on the combined effect of MeJA on cell cycle together with a true and strong elicitor like CD. Further experiments will be required to confirm this possibility on the interaction between cell cycle and secondary metabolite biosynthetic gene expression.

\section{Methods}

\section{Establishment of calli and cell suspension cultures}

Vitis vinifera L. cv. Monastrell albino calli were established as previously described [24]. Cell suspensions were established and maintained as described by Bru et al. [14].

\section{Elicitation of Monastrell albino cell cultures}

Elicitation experiments were carried out on three replicates of 14 days old grapevine cell suspensions. Washed cells (20 g FW) were transferred into $250 \mathrm{ml}$ flask and resuspended in $100 \mathrm{ml}$ of sterile fresh medium containing either $50 \mathrm{mM}$ DIMEB, $100 \mu \mathrm{M}$ MeJA or $50 \mathrm{mM}$ DIMEB + $100 \mu \mathrm{M}$ MeJA. Control cultures contained no additional DIMEB or MeJA. In order to assess for any effect on cell growth of the ethanol used to deliver the MeJA, we carried out biomass measures in control cell suspensions treated with $0.2 \% \mathrm{v} / \mathrm{v}$ ethanol during the experimental set up. There were no significant differences in cell growth between ethanol-treated and non-treated control cell suspensions (data not shown). All cell suspensions were incubated for up to $168 \mathrm{~h}$ at $25^{\circ} \mathrm{C}$ in darkness in a rotary shaker $(110 \mathrm{rpm})$ and a cell growth time course was performed both for treated and control cells. After elicitation, cells were filtered from the spent medium under gentle vacuum, rapidly washed with cold distilled water, 
Table I: Primer pairs used for real time quantitative RT-PCR

\begin{tabular}{|c|c|c|c|c|c|}
\hline Gene abbreviation & Gene definition & GenBank accession & Unigene ID & $\begin{array}{c}\text { Primer pair } \\
\left(5^{\prime} \text {-forward-3'/5'-reverse-3') }\right.\end{array}$ & $\begin{array}{l}\text { Product size } \\
\quad \text { (bp) }\end{array}$ \\
\hline STSI & Stilbene synthase I & DQ36630I & Vvi.8 & $\begin{array}{l}\text { CGAAGCAACTAGGCATGTGT/ } \\
\text { CTCCСCAATCCAATCСTTCA }\end{array}$ & 134 \\
\hline STS2 & Stilbene synthase 2 & DQ366302 & Vvi.8 & $\begin{array}{l}\text { ACCAAAGTCCAAGATCACCCA/ } \\
\text { ACAACATCACCCTTCTAACCGAT }\end{array}$ & 122 \\
\hline PALI & Phenylalanine ammonia lyase & $\underline{E C 987386}$ & Vvi. 1950 & $\begin{array}{l}\text { CCGAACCGAATCAAGGACTG/ } \\
\text { GTTCCAGCCACTGAGACAAT }\end{array}$ & 183 \\
\hline $\mathrm{C} 4 \mathrm{HI}$ & Cinnamate-4-hydroxylse & EC995763 & Vvi.6228 & $\begin{array}{l}\text { AAAGGGTGGGCAGTTCAGTT/ } \\
\text { GGGGGGTGAAAGGAAGATAT }\end{array}$ & 109 \\
\hline $4 \mathrm{CLI}$ & 4-coumarate-CoA ligase & EC947790 & Vvi.I25I & $\begin{array}{l}\text { CTGATGCCGCTGTTGTTTCG/ } \\
\text { GCAGGATTTTACCCGATGGA }\end{array}$ & 198 \\
\hline $\mathrm{CHSI}$ & Chalcone synthasel & EC996578 & Vvi.II7 & $\begin{array}{l}\text { GTCCCAGGGTTGATTTCCAA/ } \\
\text { TCTCTTCCTTCAGACCCAGTT }\end{array}$ & 157 \\
\hline $\mathrm{CHS} 2$ & Chalcone synthase 2 & EC996527 & Vvi.1973 & $\begin{array}{l}\text { TTTGGGCATCAAGGACTGGA/ } \\
\text { CTCGGGCTTTAGGGCTAAT }\end{array}$ & 100 \\
\hline CCR2 & Cinnamoyl-CoA reductase & CF517687 & Vvi.I5864 & $\begin{array}{l}\text { ACAGCATGACGACTCTCTTCG/ } \\
\text { AGTGACAAGGGGTGGATTGA }\end{array}$ & 182 \\
\hline
\end{tabular}

weighted and frozen at $-80^{\circ} \mathrm{C}$ until use. The spent medium was used for stilbenoids analysis.

\section{Analysis of stilbenoids in the spent medium and in cells} Samples were analyzed by liquid chromatography according to Dalluge et al. [25] with modifications in an Agilent 1100 series HPLC equipped with UV-vis and ESI-MS detectors. For more details, see Additional File 2. A time course of stilbenoid production was also performed up to $168 \mathrm{~h}$ of cell culture.

\section{RNA isolation, cDNA synthesis and Real-time quantitative RT-PCR (qRT-PCR)}

Total RNA was extracted from frozen cells ( 0.5 g FW) by means of the TRIZOL reagent (INVITROGEN) following the manufacture's recommendations. cDNA synthesis and qRT-PCR procedures were performed according to Reid et al. [26]. Grapevine gene specific primers were designed using the Oligo Explorer 1.2 software (Gene Link). Primer sequences used in the GRT-PCR analyses are presented in Table 1. Data were analyzed using the 7300 SDS software 1.3 (Applied Biosystems). Transcript level was calculated using the standard curve method and normalized against grapevine EF $\alpha 1$ gene (UniGene Vvi.1750) used as reference control. Relative expression of the different genes was analyzed at five time points.

\section{Competing interests}

The authors declare that they have no competing interests.

\section{Authors' contributions}

DL designed the study, performed qRT-PCR and statistical analysis, coordinated the study and drafted the manuscript. LA performed the cell culture work and qRT-PCR analysis. SBN performed the cell culture work. JMMZ participated in the design of the study and the manuscript drafting. RB and MAP coordinated the cell culture work, participated in the design of the study and the manuscript drafting. All authors read and approved the final manuscript.

\section{Additional material}

\section{Additional file 1}

Cell viability of grapevine cell suspension cultures treated with MeJA. Cell viability was evaluated by incubating the cells for 1-2 min in fresh Gamborg medium containing $100 \mu \mathrm{g} \mathrm{ml-1}$ fluorescein diacetate. Fluorescence was observed with a DMRB Leica microscope using a Leica filter ( $(\lambda e x c=$ $490 \mathrm{~nm}, \lambda e m i=520 \mathrm{~nm})$. (a) and (b) bright field (40×), (c) and (d) UV light $(40 \times),(e)$ and $(f) 10 \times$ zoom-in.

Click here for file

[http://www.biomedcentral.com/content/supplementary/17560500-1-132-S1.png] 


\section{Additional file 2}

Chromatographic profile of culture medium (A) and cell extract (B) at $168 \mathrm{~h}$. One volume of culture medium is diluted with two volumes of water and twelve of pure methanol. Fifty mg of freeze-dried cells were extracted overnight in $4 \mathrm{~mL}$ methanol at $4^{\circ} \mathrm{C}$. The extract was diluted with water to a final concentration of $80 \%(v / v)$ methanol. Then $30 \mu \mathrm{L}$ of diluted medium is analyzed by HPLC. Elution of stilbenoids was recorded at $306 \mathrm{~nm}$ and compounds are detected by mass spectrometry. Authentic resveratrol (Sigma), t-Piceid (Chromadex) were used for compound confirmation and quantification. The cis- isomers were obtained by exposure to UV light of the trans- and used for quantification in the same manner.

Click here for file

[http://www.biomedcentral.com/content/supplementary/17560500-1-132-S2.pdf]

\section{Additional file 3}

Analysis of stilbenoids in cells at $168 \mathrm{~h}$. Values (in $\mu$ mole $\mathrm{gDW}^{-1}$ ) are given as the mean \pm standard deviation of three replicates. For methodological details, see Additional File 2.

Click here for file

[http://www.biomedcentral.com/content/supplementary/17560500-1-132-S3.pdf]

\section{Acknowledgements}

SBN and LA hold grants from the Fundación Séneca. We thank Lucie Fernandez for helpful comments on qRT-PCR and Pepita Alemán for maintaining Monastrell albino cell cultures. This work has been partially supported by the MEC and FEDER (BIO2005-00332), Consejería de Educación, Ciencia e Investigación de la Región de Murcia (2105SU0020 and BIO-BVA 07/0I0003) and the GrapeGen project (a joint international project funded by Genoma España and Genome Canada).

\section{References}

I. Langcake P, Pryce RJ: A new class of phytoalexins from grapevines. Experientia 1977, 33(2): I5I-I52.

2. Jeandet P, Douillet-Breuil AC, Bessis R, Debord S, Sbaghi M, Adrian M: Phytoalexins from the Vitaceae: biosynthesis, phytoalexin gene expression in transgenic plants, antifungal activity, and metabolism. Journal of Agricultural and Food Chemistry 2002, 50:273|-274|

3. Pezet R, Gindro K, Viret O, Richter H: Effects of resveratrol, viniferins and pterostilbene on Plasmopara viticola zoospore mobility and disease development. Vitis 2004, 43: I45-I48.

4. Pezet R, Gindro K, Viret O, Spring JL: Glycosylation and oxidative dimerization of resveratrol are respectively associated to sensitivity and resistance of grapevine cultivars to downy mildew. Physiological and Molecular Plant Pathology 2004, 65:297-303.

5. Wieder T, Prokop A, Bagci B, Essmann F, Bernicke D, Schulze-Osthoff K, Dörken B, Schmalz HG, Daniel PT, Henze G: Piceatannol, a hydroxylated analog of the chemopreventive agent resveratrol, is a potent inducer of apoptosis in the lymphoma cell line BJAB and in primary, leukemic lymphoblasts. Leukemia 200I, I 5: I735-1742.

6. de la Lastra CA, Villegas I: Resveratrol as an antioxidant and prooxidant agent: mechanisms and clinical implications. Biochemical Society Transactions 2007, 35: I I 56- II60.

7. Commun K, Mauro MC, Chupeau Y, Boulay M, Burrus M, Jeandet P: Phytoalexin production in grapevine protoplasts during isolation and culture. Plant Physiology et Biochemistry 2003 4I:317-323.

8. Krisa S, Larronde F, Budzinski H, Decendit A, Deffieux G, Mérillon JM: Stilbene production by Vitis vinifera cell suspension cultures: methyl jasmonate induction and ${ }^{13} \mathrm{C}$ biolabeling. Journal of Natural Products 1999, 62:1688-1690.
9. Gundlach $\mathrm{H}$, Muller MJ, Kutchan TM, Zenk MH: Jasmonic acid is a signal transducer in elicitor-induced plant cell cultures. Proceedings of the National Academy of Sciences of the United States of America 1992, 89:2389-2393.

10. Larronde F, Gaudillere JP, Krisa S, Decendit A, Deffieux G, Merillon JM: Airborne methyl jasmonate induces stilbene accumulation in leaves and berries of grapevine plants. American Journal of Enology and Viticulture 2003, 54:63-66.

II. Repka V, Fischerová I, Šilhárová K: Methyl jasmonate is a potent elicitor of multiple defense responses in grapevine leaves and cell-suspension cultures. Biologia Plantarum 2004, 48:273-283.

12. Tassoni A, Fornale S, Franceschetti M, Musiani F, Michael AJ, Perry B, Bagni $\mathrm{N}$ : Jasmonates and $\mathrm{Na}$-orthovanadate promote resveratrol production in Vitis vinifera cv. Barbera cell cultures. New Phytologist 2005, 166:895-905.

13. Morales M, Bru R, García-Carmona F, Ros Barceló A, Pedreño MA: Effect of dimethyl- $\beta$-cyclodextrins on resveratrol metabolism in Gamay grapevine cell cultures before and after inoculation with shape Xylophilus ampelinus. Plant Cell, Tissue and Organ Culture 1998, 53:179-187.

14. Bru R, Selles S, Casado-Vela J, Belchi-Navarro S, Pedreño MA: Modified cyclodextrins are chemically defined glucan inducers of defense responses in grapevine cell cultures. Journal of Agricultural and Food Chemistry 2006, 54:65-7I.

15. Bru R, Pedreño MA: Method for the production of resveratrol in cell cultures. PCT Patent WO/2003/062406 2003.

16. Kiselev KV, Dubrovina AS, Veselova MV, Bulgakov VP, Fedoreyev SA, Zhuravlev YN: The rolB gene-induced overproduction of resveratrol in Vitis amurensis transformed cells. Journal of Biotechnology 2007, I 28:68I-692.

17. Saigne-Soulard C, Richard T, Mérillon JM, Monti JP: I3C NMR analysis of polyphenol biosynthesis in grape cells: Impact of various inducing factors. Analytica Chimica Acta 2006, 563:137-I44.

18. Pauwels L, Morreel K, De Witte E, Lammertyn F, Van Montagu M, Boerjan W, Inze D, Goossens A: Mapping methyl jasmonatemediated transcriptional reprogramming of metabolism and cell cycle progression in cultured Arabidopsis cells. Proceedings of the National Academy of Sciences 2008, 105: I380.

19. Hall D, De Luca V: Mesocarp localization of a bi-functional resveratrol/hydroxycinnamic acid glucosyltransferase of Concord grape (Vitis labrusca). The Plant Journal 2007, 49:579-59I.

20. Bru R, Lopez-Nicolas JM, Nunez-Delicado E, Nortes-Ruiperez D, Sanchez-Ferrer A, Garcia-Carmona F: Cyclodextrins as hosts for poorly water-soluble compounds in enzyme catalysis. Applied biochemistry and biotechnology 1996, 61:189-198.

21. Naill MC, Roberts SC: Cell cycle analysis of Taxus suspension cultures at the single cell level as an indicator of culture heterogeneity. Biotechnology and Bioengineering 2005, 90:49I-500.

22. Naoumkina M, Farag MA, Sumner LW, Tang Y, Liu C-J, Dixon RA: Different mechanisms for phytoalexin induction by pathogen and wound signals in Medicago truncatula. Proceedings of the National Academy of Sciences 2007, I04:17909-17915.

23. Zhao J, Davis LC, Verpoorte R: Elicitor signal transduction leading to production of plant secondary metabolites. Biotechnology Advances 2005, 23:283-333.

24. Calderon AA, Zapata JM, Munoz R, Pedreño MA, Barcelo AR: Resveratrol production as a part of the hypersensitive-like response of grapevine cells to an elicitor from Trichoderma viride. New Phytologist 1993, 124:455-463.

25. Dalluge JJ, Nelson BC, Thomas JB, Sander LC: Selection of column and gradient elution system for the separation of catechins in green tea using high-performance liquid chromatography. Journal of chromatography A 1998, 793:265-274.

26. Reid KE, Olsson N, Schlosser J, Peng F, Lund ST: An optimized grapevine RNA isolation procedure and statistical determination of reference genes for real-time RT-PCR during berry development. BMC Plant Biology 2006, 6:27. 